\title{
Retração, Progressão, Expansão e Retrocesso: o Caminho Higido para um Sistema de Proteção Social Sustentável
}

\author{
André Studart Leitão \\ Eduardo Rocha Dias** \\ Alexandre Antonio Bruno da Silva**
}

Introdução. 1 Sistema, coerência e abertura cognitiva. 2 Estruturação, expansão e retração. 3 Sobre reformas, sustentabilidade e retrocesso social. Considerações finais. Referências.

\section{RESUMO}

Mudanças ocorrem a todo momento, impondo ajustes e calibrações nas normas que regulam as relações humanas. No campo dos direitos sociais, a realidade não é diferente. Fatores exógenos, como as guerras, além da evolução socioeconômica e dos avanços tecnológicos, passaram a reclamar uma postura mais enérgica do Estado, que deixou de ser um ente absenteísta, para se transformar em um agente normalizador das relações jurídicas, com forte intervenção protetiva. Porém, o gigantismo estatal, o crescimento desordenado do sistema protetor e o crônico desequilíbrio das contas públicas, aliados a mudanças demográficas, passaram a revelar claros sinais de retração do modelo de proteção hipertrófica. A realidade brasileira também experimentou a incômoda transição entre os modelos de expansão e de retração dos direitos, com duas ressalvas: no Brasil, os esquemas de proteção não foram propriamente construídos, mas importados de outros países e entregues ao povo como donativos e ofertas políticas, instituídas sem um planejamento minimamente adequado. $\mathrm{O}$ resultado da imprudência legislativa foi a constatação de que um sistema protetor vulnerável possui durabilidade efêmera, o que leva à necessidade de reformas veiculadas por meio de medidas de contenção e de austeridade. O trabalho procura salientar sobretudo três aspectos: $1^{\circ}$ ) a importância de um planejamento

* Mestre e Doutor em Direito das Relações Sociais pela PUC-SP. Procurador Federal. Professor no Centro Universitário Christus. E-mail: andrestudart@hotmail.com.

** Doutor em Direito pela Universidade de Lisboa. Mestre em Direito pela Universidade Federal do Ceará. Procurador Federal. Professor do Programa de Pós-Graduação em Direito da Universidade de Fortaleza. E-mail: eduardordias@hotmail.com.

*** Mestre em Direito pela UFC. Doutor em Direito pela PUC-SP. Auditor-Fiscal do Trabalho. Professor no Centro Universitário Christus. E-mail: alexandre_bruno@terra.com.br. 
cauteloso na instituição de um modelo seguro e sustentável de proteção social; $2^{\circ}$ ) a imprescindibilidade de reformas e ajustes normativos para readequar generosos critérios de seletividade; e 3०) a implementação de medidas de contenção, conquanto implique a redução do padrão de qualidade protetiva, não caracteriza retrocesso social, mas a retomada do caminho rumo ao equilíbrio, à sustentabilidade e à coerência.

Palavras-chave: Benefícios sociais. Retrocesso social. Reformas no Estado de Bem-estar Social.

\section{INTRODUÇÃO}

Este artigo possui dois pontos de partida. O primeiro é que tudo, em algum momento, sofre alteração. Ainda na Antiguidade, Heráclito de Éfeso, filósofo pré-socrático, defendia que a única constante do universo era a mudança. "Tudo flui, nada persiste nem permanece o mesmo" ${ }^{1}$. Metaforicamente, um mesmo homem não conseguiria entrar duas vezes no mesmo rio. Interações entre estruturas independentes, ainda que mínimas, desencadeiam perturbações e sucessivas transformações ontogênicas, sem falar das variantes resultantes da própria dinâmica interna ${ }^{2}$.

O segundo pressupõe que o homem, principal personagem desse permanente processo de ressignificação e reconstrução, instintiva e naturalmente, procura inserir-se em grupos sociais. Ora, se mudanças geram mudanças, toda e qualquer ação provoca uma reação no campo relacional. Esse interminável ciclo comportamental desencadeia um movediço cenário de instabilidade, que leva à necessidade de recorrer ao Direito para padronizar regras e condutas.

Mas a efetividade da norma também depende de sucessivas alterações, até porque não existe regra absoluta dentro de uma sociedade metamórfica. Portanto, reformas e ajustes normativos são indispensáveis para a garantia do equilíbrio das relações jurídicas. No que diz respeito aos direitos sociais, segue-se o mesmo padrão, com um elemento acelerador adicional. Além das mudanças decorrentes da própria dinâmica interna dos grupos, ao longo da história, ocorreram fatores exógenos, como a industrialização e as guerras, que precipitaram sobremaneira a trajetória evolutiva das relações humanas. Mudanças fáticas aconteceram e exigiram readequações normativas. Os direitos sociais passaram por um processo de hipertrofia, que levou ao agigantamento do Estado (Welfare State) e ao aumento significativo da despesa pública.

A realidade brasileira é peculiar, pois aqui as mudanças não decorreram propriamente de fatores exógenos, mas da importação e replicação pacífica de conceitos e esquemas protetivos sem um planejamento minimamente adequado. Com efeito, pouco tempo depois da redemocratização, passou-se a experimentar, com deleite, a tentadora sensação de um sistema protetor paternalista estruturado em premissas universais, com desmedida e imprudente ampliação da rede de 
proteção, por meio da instituição, extensão e majoração de benefícios, sem considerar que, como todo e qualquer direito, há custos diretos e indiretos envolvidos ${ }^{3}$.

Não tardou muito para que o gigantismo estatal, o crescimento desordenado do sistema protetor e o crônico desequilíbrio das contas públicas, aliados a mudanças demográficas, revelassem os claros sinais de retração do modelo brasileiro de proteção hipertrófica. No final de 2014, medidas de contenção, materializadas por meio de descartes de direitos sociais, abruptamente, tornaram-se pauta prioritária do governo federal brasileiro.

Essa volatilidade inerente ao grupo de normas de caráter social, que aliás lembram o mecanismo de funcionamento de uma sanfona, demanda algumas reflexões: expansões protetivas não planejadas podem ser consideradas um novo estágio de evolução da sociedade? Existe alguma vantagem em construir um sistema protetor efêmero, insustentável e consequentemente inseguro? Descartes de direitos sociais necessariamente caracterizam retrocesso social ou, eventualmente, representam ajustes necessários para a sobrevivência e a sustentabilidade do regime?

\section{SISTEMA, COERÊNCIA E ABERTURA COGNITIVA}

Para que se possa falar de ordem, é necessário que os entes que a constituem não estejam somente em relacionamento com o todo, mas também num relacionamento de coerência entre $\mathrm{si}^{4}$.

Por consectário, constitui inegável pressuposto de sustentabilidade do sistema protetor a articulação adequada dos componentes da seguridade social (previdência e assistência), de modo a evitar mecanismos sobrepostos de proteção e o consequente esvaziamento da previdência social, de caráter contributivo. Não pode haver concorrência e interseções entre os subsistemas da seguridade social.

Sob outra perspectiva, os sistemas sociais são autopoiéticos. Não podem ser determinados pelo ambiente. Todas as operações internas decorrem de processos comunicativos próprios e exclusivos, que garantem unidade e identidade do sistema. Essa autonomia do sistema tem por condição sua clausura, quer dizer, a circunstância de ele ser fechado, do ponto de vista de sua organização, não havendo entradas (inputs) e saídas (outputs) para o ambiente ${ }^{5}$.

Contudo, o fechamento operacional do sistema não exclui a sua conexão com o ambiente. Cognitivamente, o sistema é aberto. Portanto, as informações externas (do ambiente) caracterizam irritações, perturbações e ruídos e desencadeiam operações próprias do sistema mediante a utilização de elementos internos preexistentes. Vale dizer: o ambiente gera o estímulo, e o sistema processa essas informações com operações que lhe são próprias.

Partindo da concepção luhmanniana, pode-se então dizer que a seguridade social é um sistema operacionalmente fechado, assenhoreado de elementos de funcionamento próprios. A estrutura normativa do sistema protetor, conquanto 
imatura e vulnerável, encontra-se consolidada. Porém, não há como desconsiderar as perturbações do ambiente social. Suas interferências provocam a necessidade de o sistema abrir-se cognitivamente e processar essas informações de modo a viabilizar a produção de novos elementos, materializados por meio de ajustes normativos ou reformas.

Destarte, as reformas e os ajustes não passam de reações do sistema às interferências externas, sempre com o intuito de buscar a coerência e o equilíbrio sistemáticos.

\section{ESTRUTURAC̣ÃO, EXPANSÃO E RETRAC̣ÃO}

Embora tenham sido implementadas medidas pontuais de contenção ${ }^{6}$, não há dúvida de que, entre os anos de 1988 e 2014, o sistema protetor brasileiro expandiu consideravelmente. $O$ marco normativo da era de expansão foi a Constituição da República de 1988, que replicou o modelo de proteção social construído na Inglaterra na década de 1940 por meio do Plano Beveridge.

Promulgada a Carta de 1988, em menos de cinco anos, estruturaram-se o sistema único de saúde (1990), de acesso universal, a previdência social, única faceta contributiva da seguridade social, e finalmente a assistência social, prestada independentemente de qualquer contrapartida (1993). Tem-se, pois, a primeira constatação: o quê, em outros países, demorou décadas ou séculos para acontecer, no Brasil, fez-se em aproximadamente cinco anos.

A impressionante velocidade de estruturação do sistema brasileiro de proteção social, por si só, demonstra a ausência de um planejamento adequado. Em acréscimo, ao longo das últimas três décadas, nos três Poderes da República, consolidou-se, com raríssimas ressalvas, um modelo de Estado paternalista. Com efeito, no âmbito normativo, seja por iniciativa do Congresso Nacional ou do próprio Governo Federal, benefícios pecuniários foram criados, majorados e estendidos sem um estudo atuarial consistente. Já na esfera judicial, com fundamento no princípio da dignidade da pessoa humana, intensificou-se a utilização da técnica de decisão pautada na flexibilização de critérios de seletividade para viabilizar a proteção a hipossuficientes.

Pois bem, não existe ação sem consequência. A improvisação, o oportunismo político e a trajetória desmedida de gasto implementada pelos Poderes Públicos nas últimas décadas provocaram efeitos colaterais.

Evidentemente, a principal implicação da ausência de um planejamento adequado foi a multiplicação da despesa pública sem a correspondente fonte de custeio, o que, aliás, conspurca frontalmente o art. 195, § 5º da Constituição da República. Contudo, as implicações transcenderam o plano sistemático da seguridade social e passaram a comprometer o equilíbrio macroeconômico do país.

Durante anos, encobriram-se e manipularam-se relevantes dados socioeconômicos que conduziam à impressão de que o país respirava uma economia ro- 
busta e vigorosa. A título de ilustração, citam-se as estatísticas de empregabilidade. O Brasil encerrou o ano de $2014 \mathrm{com}$ a menor taxa de desemprego registrada em sua história recente: incríveis 4,8\%? Supreendentemente, para o ano de 2016, já se estima (ou subestima) uma taxa de desemprego da ordem de $10 \%{ }^{8}$. Como isso é possível? Certamente, um dos fatores que levou ao avanço do desemprego foi o duro golpe sofrido pela iniciativa privada em razão da "abrupta" e "inesperada" crise econômica "descoberta" no final de 2014. Mas não foi o único. Segundo os dados oficiais do IBGE, há poucos meses, a cada 100 brasileiros em idade laborativa, 53 trabalhavam, três procuravam emprego e não encontravam, e 44 não trabalhavam e nem procuravam emprego. Considerando-se que o critério de medida do desemprego leva em consideração não o quantitativo das pessoas sem ocupação, mas das que efetivamente procuram emprego, há aproximadamente um ano, propalava-se a notícia de que quase todos os brasileiros tinham emprego. $\mathrm{Na}$ realidade, quase metade não tinha .

Uma das principais causas para que tantos brasileiros sem ocupação não tivessem (e não tenham) interesse de se posicionar no mercado de trabalho, curiosamente, decorre dos programas sociais do governo. Benefícios como o Bolsa Família geram condições de sobrevivência para milhões de famílias e desestimulam a busca pelo emprego, sobretudo pelo risco de obliteração do amparo público em virtude da percepção de renda formal.

Note-se ainda que a opção pelo "não trabalho" ou pelo "trabalho informal", mais à frente, demanda novo amparo estatal, dessa vez mediante a concessão do benefício assistencial de prestação continuada, prestação de um salário mínimo que também independe de qualquer contrapartida tributária.

Apenas para ilustrar a enorme dimensão subjetiva do benefício assistencial, em 2012, ele já amparava 1,7 milhões de idosos e 1,9 milhões de pessoas com deficiência ${ }^{10}$. Um dos fatores que levou ao aumento significativo do número de beneficiários foi a redução do limite etário aplicável ao benefício para o idoso. Com efeito, segundo a redação original da Lei 8.742/93, a idade exigida para o amparo assistencial era setenta anos de idade (art. 20). Após a Lei 9.720/1998, decorrente da conversão da Medida Provisória 1.599-51, o benefício passou a ser devido a partir de sessenta e sete anos. Enfim, nova redução etária foi implementada pelo art. 34 da Lei 10.741/2003 (Estatuto do Idoso). Desde então, a prestação passou a ser devida a partir dos sessenta e cinco anos.

Note-se que a despesa pública decorrente do amparo social para o idoso não decorre exclusivamente da antecipação cronológica do benefício. Nos últimos anos, a expectativa de vida do brasileiro evoluiu bastante. Vale dizer: enquanto o legislador se encarregou de antecipar normativamente o direito ao benefício, as mudanças demográficas provocaram a manutenção do benefício por mais tempo.

Além do mais, deve-se ponderar que a idade de sessenta e cinco anos é idêntica à exigida para a aposentadoria por idade urbana dos segurados do sexo masculino e contribui para uma concorrência indesejada entre os subsistemas 
previdenciário e assistencial. O nível de generosidade e de acessibilidade a prestações não contributivas afeta negativamente o mercado de trabalho, impelindo para a informalidade trabalhadores que poderiam, de outro modo, contribuir, mas que se fiam na possibilidade de obtenção de um benefício não contributivo, principalmente se esse tem um valor equivalente ao de benefícios contributivos ${ }^{11}$.

Ainda sobre o benefício assistencial de prestação continuada, outro pressuposto de concessão indicado constitucionalmente (art. 203, V, da CF/88) envolve a demonstração da hipossuficiência econômica do grupo familiar. A regulamentação dessa exigência constitucional foi materializada pelo parágrafo 3o do art. 20 da Lei 8.742/93, que considera incapaz de prover a manutenção da pessoa com deficiência ou idosa a família cuja renda mensal per capita seja inferior a $1 / 4$ (um quarto) do salário-mínimo.

Provocado a respeito da razoabilidade desse critério objetivo de miserabilidade, em 1998, o STF considerou-o constitucional (ADI 1.232-DF e RE 276.854-SP), por entender que o legislador ordinário poderia estabelecer uma hipótese objetiva de intuito selecionador.

Não obstante o posicionamento firmado pelo STF, a matéria continuou sendo alvo de discussão nos Tribunais. O STJ, por exemplo, vinha considerando o critério descrito no art. $20, \S 3^{\circ}$ da Lei 8.742/93 como um limite mínimo, um quantum objetivamente insuficiente à subsistência da pessoa com deficiência e do idoso, sem prejuízo da possibilidade de conjugação de outros fatores que comprovassem a vulnerabilidade econômica do grupo familiar (renda da família $\mathrm{x}$ despesas com moradia, alimentação, medicamentos etc. $)^{12}$.

O tema voltou a ser discutido pelo STF em 2013, durante o julgamento da Reclamação 4374 e dos Recursos Extraordinários 567.985 e 580.963. Ao final, o Tribunal concluiu pela ocorrência do processo de inconstitucionalização decorrente de notórias mudanças fáticas (políticas, econômicas e sociais) e jurídicas (sucessivas modificações legislativas dos patamares econômicos utilizados como critérios de concessão de outros benefícios assistenciais por parte do Estado brasileiro). Por essa razão, declarou a inconstitucionalidade parcial, sem pronúncia de nulidade, do art. 20, § 3o, da Lei no 8.742/1993.

Em linguagem direta: entendeu-se que o critério objetivo impugnado (renda per capita inferior a um quarto do salário mínimo) estava defasado em virtude do advento de leis posteriores com critérios mais generosos para a concessão de outros benefícios assistenciais (renda per capita inferior a meio salário mínimo). Também se decidiu que o Poder Judiciário dispunha de autoridade para apreciar a prova dos autos livre de qualquer parâmetro objetivo. Percebe-se, pois, a consagração e legitimação da ideia de justiça lotérica, tão veementemente combatida por Lênio Streck, um dos mais festejados juristas brasileiros da atualidade ${ }^{13}$.

Realmente, a abertura excessiva do critério semântico da hipótese de incidência protetiva gera pronunciamentos judiciais de vários matizes, com enorme custo à segurança jurídica. Não existe estabilidade quando a solução de conflitos 
depende exclusivamente do casuísmo. Ao contrário, o modelo de fastígio do Judiciário, ao invés de pacificar relações, estimula a litigiosidade, a judicialização, a insegurança e o aumento do gasto público.

Outro bom exemplo de expansão protetiva implementada sem um estudo atuarial consistente foi a majoração do benefício de pensão por morte. Em aproximadamente cinco anos (entre 1990 e 1995), o percentual básico de cálculo da pensão previdenciária saltou de 50\% para $100 \%$. Cerca de vinte anos depois, a Presidente da República editou uma medida provisória (MP 664/14) reduzindo novamente a parcela básica do benefício para $50 \%$, como parte integrante de um ajuste fiscal de urgência indispensável para a recuperação da economia nacional $^{14}$. Na Exposição de Motivos da MP 664/14, ressaltou-se, basicamente, o crescimento desproporcional das despesas sociais.

2. Cabe salientar que, em função do processo de envelhecimento populacional, decorrente da combinação de queda da fecundidade e aumento da expectativa de vida, haverá um aumento da participação dos idosos na população total e uma piora da relação entre contribuintes e beneficiários. A participação dos idosos na população total deverá crescer de 11,3\%, em 2014, para 33,7\% em 2060, conforme dados da projeção demográfica do IBGE. Como resultado, o relatório de avaliação atuarial e financeira do RGPS, que faz parte dos anexos do Projeto de Lei de Diretrizes Orçamentárias (PLDO), estima o crescimento da despesa, em \% do PIB, do atual patamar de 7\% para cerca de 13\% em 2050. O artigo 201 da Constituição estabelece que a Previdência Social deverá ser organizada sob a forma de regime geral, de caráter contributivo e de filiação obrigatória, observados critérios que preservem o equilibrio financeiro e atuarial. [...]

5. A despesa bruta com pensão por morte no âmbito do RGPS cresceu do patamar de $\mathrm{R} \$ 39$ bilhões, em 2006, para $\mathrm{R} \$ 86,5$ bilhões em 2013 e, portanto, mais que dobrou em valores nominais no período (alta de $121,5 \%$ ), com um crescimento médio anual de cerca de $12 \%$ a.a.. Em termos da despesa em \% do PIB, os pagamentos com pensão passaram de 1,6\% do PIB, em 2006, para cerca de 1,8\% em 2013, apenas considerado o RGPS, sem levar em consideração os Regimes Próprios de Previdência dos servidores públicos. A quantidade de pensões emitidas e a duração média do benefício também têm crescido ao longo do tempo. O total de pensões no âmbito do RGPS passou de 5,9 milhões, em dezembro de 2005, para cerca de 7,4 milhões em outubro de 2014, um incremento de cerca de 1,5 milhão no período. A duração média dos benefícios cessados passou do patamar de 13 anos, em 1999, para 16 anos em 2012, reflexo, entre outros fatores, do aumento da expectativa de vida e sobrevida e das atuais regras de concessão. Considerando as pensões por morte cessadas em 2013, cerca de 20,3 mil tiveram duração de 35 anos ou mais. Esse impacto na duração afeta, consequentemente, a despesa total com esses bene- 
fícios, na medida em que essa despesa é resultado do produto do valor do benefício pelo tempo em que são pagos. $\mathrm{O}$ incremento da despesa por si só não é um problema, quando representa maior nível de proteção, mas certamente não é recomendável quando decorre de regras inadequadas de concessão e também pressiona a carga tributária. [... $]^{15}$

O Bolsa Família, principal programa assistencial de transferência de renda, também seguiu a trajetória de expansão seguida de retração. Em doze anos (entre $2003^{16}$ e 2015), o gasto com o Bolsa Família saltou de R \$ 7,5 bilhões para $\mathrm{R} \$ 27,1$ bilhões ${ }^{17}$. Mais recentemente, o relator-geral do Orçamento de 2016, deputado Ricardo Barros (PP-PR), confirmou no parecer final um corte de R $\$ 10$ bilhões no Bolsa Família, o que representa o equivalente a 35\% do orçamento disponível para o benefício no ano de 2015.

Pois bem, mesmo aos olhos de uma pessoa sem formação em atuária, é facilmente perceptível que as alterações socioeconômicas, financeiras e demográficas, desde há muito, vêm provocando o crescimento progressivo do gasto público de caráter prestacional. Portanto, certamente, o desequilíbrio das contas públicas não decorreu de causas extraordinárias, mas da falta de planejamento atuarial.

○ fato é que, no Brasil, o Estado-legislador, definitivamente, não planeja a proteção sustentável. Propostas de ampliação da rede protetiva são frequentemente discutidas no parlamento, com raras ponderações sobre o seu impacto econômico e nenhuma investigação quanto à sua sustentabilidade. Em verdade, na maioria das vezes, a aprovação de um programa social ou de uma expansão protetiva é comemorada como uma conquista pessoal ou partidária, invocada oportunamente pelo suposto idealizador como parte integrante de sua herança política. Em outros casos, as deliberações do Congresso Nacional, claramente, são utilizadas como mecanismo de pressão política, sem nenhum comprometimento com os interesses do povo. $\bigcirc$ planejamento e a técnica securitária e atuarial são esquecidos, secundarizados, em detrimento de interesses políticos imediatos e escusos.

Ora, no cenário contemporâneo, em que a sociedade produz e consome o próprio risco, conforme a conhecida fórmula "sociedade de risco", de Ulrich Beck, a lógica de proteger sem nenhuma contrapartida e substância atuarial, definitivamente, não pode ser considerada um bom mecanismo de seletividade.

Não se questiona a eficiência de um sistema protetor de abrangência universal em pleno funcionamento, mas a sua sustentabilidade a médio e longo prazos, sobretudo em um país onde milhões de pessoas dependem substancialmente do amparo estatal.

Da mesma forma, também não se defende a concepção ultraliberal adotada por Roberto Nozick, segundo a qual o Estado mínimo, que se restrinja basicamente à segurança pública, é justificado; que qualquer Estado mais abrangente viola os direitos de as pessoas não serem obrigadas a fazer determinadas coisas ${ }^{18}$. 
Deve-se, isto sim, buscar o equilíbrio entre o absenteísmo e o intervencionismo estatal. Se, de um lado, o Estado justo não pode manter-se inerte diante da miséria de seu povo, de outro, é preciso ponderar que um modelo sustentável de proteção social recomenda prudência, planejamento e coerência. Afinal, todos os direitos subjetivos públicos são positivos, e as prestações necessárias à efetivação de tais direitos têm custos, e como tal, são sempre positivas ${ }^{19}$. Em síntese: um Estado justo normaliza. Apenas isso.

Contudo, é preciso investigar se afinal a política de austeridade implementada por contundentes medidas de retração materializadas por descartes de direitos representa um ajuste necessário para a sustentabilidade ou caracteriza retrocesso social.

\section{SOBRE REFORMAS, SUSTENTABILIDADE E RETROCESSO SOCIAL}

Diferentemente dos direitos de defesa ou de primeira geração, a interferência estatal no âmbito social demanda efetivamente uma atuação positiva. Trata-se do direito às prestações, algo que não se confunde com mecanismos de controle e de fiscalização, também assegurados pelo Estado, a exemplo do direito de acesso à justiça ${ }^{20}$.

Os direitos sociais pressupõem que seja criada e colocada à disposição dos cidadãos a prestação que constitui seu objeto, já que objetivam a realização da igualdade material, no sentido de garantir a participação de todos na distribuição pública de bens materiais e imateriais ${ }^{21}$. Discrimina-se positivamente com propósitos compensatórios.

É indiscutível a vinculação de tais direitos à chamada "reserva do possível" 22 . Todos os direitos possuem custos econômicos, sobretudo aqueles que demandam uma atuação estatal positiva. Sua efetividade depende da disponibilidade de recursos materiais e econômicos (possibilidade fática) e da existência de competência para sua instituição, isto é, de poder de disposição por parte do destinatário da norma (possibilidade jurídica).

Ademais, não basta a existência de recursos materiais e de poder de disposição: é indispensável que a prestação exigida se mantenha nos limites do razoável. Assim, repugna ao princípio da razoabilidade e da proporcionalidade impor ao Estado que ofereça assistência social a quem não tem necessidade, por possuir recursos econômicos suficientes para satisfazer a referida necessidade, por exemplo.

A aplicação dos recursos estatais, por definição escassos, depende também da conjuntura socioeconômica global, uma vez que a Constituição não oferece, ela mesma, os critérios para essa decisão, deixando-a a cargo dos órgãos políticos (de modo especial ao legislador por meio da lei orçamentária) competentes para a definição das linhas gerais das políticas na esfera socioeconômica.

O Supremo Tribunal Federal, em decisão proferida na Arguição de Descumprimento de Preceito Fundamental 45 ${ }^{23}$, manifestou-se no sentido de que a 
reserva do possível pode conviver com a exigência de manutenção de um mínimo existencial. Também foi reconhecida a possibilidade de o Poder Judiciário viabilizar o acesso a bens cuja fruição haja sido injustamente recusada pelo Estado. Devem estar presentes, porém, duas condições cumulativas: inicialmente, a razoabilidade da pretensão individual ou social deduzida em face do Poder Público; em segundo lugar, a existência de disponibilidade financeira. A segunda condição é um dado inescapável. Porém, não se pode invocá-la à margem de livre conformação do legislador, quando a aplicação de recursos públicos violar, de forma evidente e arbitrária, uma incumbência constitucional dirigida ao Estado, ou quando houver uma omissão da parte deste último. Predicou-se, portanto, a necessidade de revisão do dogma da Separação de Poderes, como barreira impeditiva de um controle, por parte do Judiciário, dos gastos públicos ou da prestação de serviços públicos, nos casos em que haja um flagrante desrespeito aos cometimentos impostos ao Estado pela Lei Maior. Resta, porém, definir o que se entende por razoabilidade da pretensão deduzida. Isso impõe verificar se há injusta denegação do acesso a determinado bem da vida ou se há alternativas colocadas à disposição dos indivíduos. Também não se pode deixar de considerar a necessidade de respeitar as previsões orçamentárias e reconhecer ao Estado certa margem de definição da forma e do tempo no qual será implementado o acesso à referida política.

A definição do conteúdo dos direitos sociais, por tais razões, diferentemente dos direitos de defesa, não se encontra, grosso modo, na Constituição. Cabe ao legislador concretizá-los e definir as prestações que serão efetivamente colocadas à disposição dos cidadãos. É claro, porém, que a Constituição impõe tarefas e deveres ao legislador (sob pena até mesmo de se reconhecer uma inconstitucionalidade por omissão) e, também, estabelece parâmetros que permitem definir o alcance de cada direito social.

O legislador encontra-se ainda vinculado no sentido de não poder consagrar retrocessos inconstitucionais na regulação dos referidos direitos fundamentais. Essa proibição de "marcha a trás" é pensada mais frequentemente no âmbito dos direitos sociais ${ }^{24}$, como o direito à saúde, mas se aplica igualmente aos direitos fundamentais de primeira geração. A eliminação de regras legais concretizadoras equivaleria a retirar eficácia jurídica das normas constitucionais que são concretizadas. A regra do não retrocesso social funda-se na proteção da confiança, princípio inerente ao Estado de Direito ${ }^{25}$. Dada a função subalterna exercida pelo constituinte derivado, sua submissão ao que foi posto pelo constituinte originário, mostra-se adequado avançar que tal proibição de retrocesso também se aplica ao poder reformador da Constituição.

De acordo com o princípio do não retrocesso, uma vez alcançado determinado grau de realização, os direitos fundamentais sociais e econômicos passam a constituir, simultaneamente, uma garantia institucional e um direito subjetivo. Mas somente estaria vedado o retrocesso quanto a direitos já adquiridos, em relação aos quais, qualquer reversibilidade seria uma violação ao princípio da proteção da confiança e da segurança dos cidadãos no âmbito econômico e social, 
bem como do núcleo essencial da existência mínima decorrente do respeito pela dignidade da pessoa. Protegem-se, portanto, os "direitos prestacionais de propriedade', subjectivamente adquiridos”, os quais constituem um limite jurídico do legislador e do constituinte derivado ${ }^{26}$.

Somente a violação ao núcleo essencial dos direitos já efetivados normativamente, com graves repercussões sobre a dignidade da pessoa, desde que não acompanhada de medidas compensatórias ou alternativas, é que justifica o reconhecimento da inconstitucionalidade. Exemplos de tais retrocessos inconstitucionais seriam a extinção, por lei, do direito ao seguro-desemprego, sem nenhuma alternativa ou compensação, ou a ampliação desproporcional do tempo necessário para a aposentadoria ${ }^{27}$.

Observe-se que não se trata de reconhecer a proibição de retrocesso como um princípio geral e absoluto ${ }^{28}$. A rigor, caso assim fosse, estar-se-ia diante de uma inversão da hierarquia das normas, uma vez que o direito ordinário passaria a se sobrepor à Constituição. Haveria, ainda, o reconhecimento automático de que todas as normas ordinárias realizadoras dos direitos sociais teriam a natureza de normas de direitos fundamentais materialmente constitucionais. Por fim, seriam erodidas a liberdade de conformação do legislador e a revisibilidade das opções por ele adotadas, degradando a função legislativa à mera função de execução da Constituição, com prejuízos para o princípio democrático. Destaque-se que subjaz ao entendimento ora atacado a mundivisão determinista e ingênua de que a História caminha em um sentido único, aprioristicamente reputado como o "certo", o que, sem dúvida, desconsidera a riqueza da realidade e a complexidade dos fenômenos, além da própria liberdade dos cidadãos, decorrente da dignidade da pessoa, de traçarem democraticamente os rumos que a sociedade deve seguir. O próprio STF, ao julgar a ADI 1923, pela qual se questionou o modelo de gestão por meio de organizações sociais, pelo qual o Estado transfere a particulares a gestão de bens e serviços públicos, decidiu que cabe aos representantes democraticamente eleitos decidir a "proporção entre a atuação direta e a indireta" na prestação de serviços sociais, como a saúde, desde que o resultado constitucionalmente fixado seja atingido. Daí não haver inconstitucionalidade na opção adotada pela Lei 9.637/1998 de buscar parceiros privados para serem fomentados pelo Poder Público visando a atingir objetivos sociais ${ }^{29}$.

Parece mais adequado falar em uma graduação de situações, em que se terá, de um lado, a proibição de pura e simplesmente destruir as posições decorrentes da atuação do legislador, cuja eliminação afete a realização do direito constitucional tal qual exige a dignidade da pessoa. No outro extremo, será possível reconhecer que algumas concretizações legislativas podem alcançar o status de normas materialmente constitucionais. Obviamente, isso somente ocorrerá em situações excepcionais, em que haja um consenso "profundo e alargado que demora o seu tempo a formar-se e que não se estende nunca a pormenores de regulamentação" ${ }^{30}$. E, em uma posição intermédia, haverá a incidência do princípio da proteção da confiança e da necessidade de fundamentação dos atos 
que materializam um retrocesso, sobretudo com a invocação de princípios e bens constitucionais que amparam a atuação do legislador. O conteúdo mínimo decorrente das normas constitucionais referentes a direitos sociais impede a simples revogação de normas concretizadoras, sem o estabelecimento de alternativas e compensações ${ }^{31}$. A proteção da confiança e o princípio da proporcionalidade, por sua vez, impedem "o arbítrio ou a desrazoabilidade manifesta do 'retrocesso" 32 .

Para Jorge Reis Novais, por outro lado, da reserva do possível decorre a insustentabilidade teórica do princípio da proibição de retrocesso. Não haveria tal proibição nos direitos sociais, nem nos direitos clássicos de liberdade: todos os direitos, segundo essa perspectiva, podem se sujeitar a retrocessos, que devem, porém, ser justificados, além de atraírem a observância dos princípios que plasmam o Estado de Direito. O que importa é apresentar argumentos que justifiquem a afetação dos direitos fundamentais sociais, considerando-a uma restrição, sujeita a controle tais quais as restrições a direitos fundamentais de liberdade. Devem observar, portanto, os princípios da igualdade, da proibição de excesso, da proteção da confiança e da dignidade da pessoa ${ }^{33}$. O intuito do autor é aproximar o regime de tutela dos direitos sociais daquele tradicionalmente aplicado aos direitos de liberdade, defendendo que a diversidade de tratamento do problema das restrições aos primeiros tem conduzido, na jurisprudência portuguesa, a um enfraquecimento do seu nível de tutela, dada a dificuldade de identificar o "núcleo essencial" dos direitos sociais, o que abre as portas a intervenções restritivas não justificadas e a défices de controle jurisdicional. Não haveria direitos de liberdade, de um lado, e direitos sociais, de outro, mas sim, pura e simplesmente, direitos fundamentais, sujeitos a um regime de proteção próprio de um Estado de Direito. A abordagem que se acaba de referir conduz a um tratamento adequado da matéria e mostra-se compatível com uma ordem jurídica como a brasileira, que não contém, como no caso português, uma previsão de tratamento diferenciado para os direitos, liberdades e garantias, de um lado, e os direitos econômicos, sociais e culturais, de outro.

As alterações das normas constitucionais e legais referentes a direitos fundamentais sociais e econômicos devem, portanto, respeitar simultaneamente as seguintes condições:

a) não acarretarem a erosão do nível de proteção existente para os referidos direitos, afetando a dignidade da pessoa;

b) não serem desproporcionais e injustificadas, e virem acompanhadas, se for possível, de medidas compensatórias;

c) respeitarem as situações já constituídas em obediência ao princípio da segurança e da proteção da confiança;

d) estabelecerem regras de transição para a tutela de situações que, sem estar definitivamente constituídas, justificam a proteção de expectativas legítimas.

Sobre a letra "a" supra, tem-se que o núcleo dos direitos fundamentais, o valor primeiro que pretendem tutelar, é a dignidade da pessoa. Proíbe o referido 
valor fazer da pessoa um objeto e desconsiderar sua individualidade e os pressupostos mínimos para sua existência. Qualquer retrocesso que fira esse núcleo intangível, portanto, há de ser rechaçado.

Com referência à letra "b”, qualquer reconfiguração da concretização normativa de um direito fundamental que implique restringir seu alcance ou tornar mais gravosa a situação do cidadão necessita ser devidamente justificada. O legislador há de demonstrar que, em virtude de um relevante valor (como a justiça, por exemplo) ou de uma situação fática nova, a concretização do alcance do direito deve ser modificada. Tal modificação, porém, em atendimento ao princípio da proporcionalidade, deve ser a menos gravosa possível. Diante dos fins de interesse público a serem atingidos, devem ser buscados os meios menos onerosos para o cidadão. Qualquer medida estatal desproporcional ou excessiva, tendo em vista os referidos fins, deverá ser fulminada por lesiva ao princípio do devido processo legal na sua acepção material ou substancial, como entende a Corte Maior ${ }^{34}$. Devem ser adotados, na medida do possível, mecanismos compensatórios que possibilitem tornar menos gravosa ou onerosa a alteração normativa.

Indispensável é respeitar as situações já definitivamente constituídas, e consideradas a salvo das novas leis ou normas constitucionais mais gravosas. Trata-se de projeção do princípio da segurança jurídica. Este postulado radica, em última instância, nas mais "fundamentais exigências ético-jurídicas" e "na própria ideia de direito" 35 como um sistema aberto e permeável a valores. Mais do que por exigências científicas e metodológicas, a consideração do ordenamento jurídico como um sistema deriva de imposições axiológicas. Falar em sistema importa falar em um todo harmonicamente integrado por partes. $O$ direito não é um aglomerado de normas aleatoriamente justapostas, mas deve respeitar, se se pretende evitar o arbítrio, postulados de adequação e de unidade. A adequação se manifesta no princípio da igualdade, a impor que se deem soluções semelhantes a casos também semelhantes, conferindo dada ordem ao sistema jurídico. A unidade, por sua vez, destina-se a evitar contradições, decorrendo também do princípio da igualdade, pelo tratamento uniforme de situações similares, e também do princípio da justiça. Este último possui uma tendência generalizadora, que se manifesta na identificação de critérios gerais que permitam tratar os diferentes casos de maneira uniforme, procedendo a abstrações e reduções da complexidade do real.

A segurança jurídica, segundo a perspectiva sistemática, responde à necessidade de busca de unidade. Pela determinabilidade e previsibilidade que pretende instaurar, a segurança jurídica contribui para a afirmação do direito como sistema. Sem segurança jurídica, não há, pois, sistema jurídico.

Corolário de tal princípio é a previsão da tutela ao direito adquirido, ao ato jurídico perfeito e à coisa julgada. Tratando-se de direitos relacionados à proteção previdenciária, direitos esses que decorrem, em regra, de relações jurídicas mantidas entre o cidadão e o Estado durante longos períodos de tempo, mesmo as situações não definitivamente constituídas merecem algum tipo de proteção. Ainda que não se alcance a intangibilidade do direito adquirido ou 
do ato jurídico perfeito, tal tutela, concretizada por meio de regras de transição, destina-se a proteger expectativas legítimas dos atingidos, sua boa-fé e confiança, ou seja, o princípio da segurança jurídica ${ }^{36}$. Deve o Poder Público atuar como pessoa de bem, evitando surpresas para os cidadãos. Se a mudança, entretanto, mostra-se necessária e indispensável, deve ser feita da maneira menos gravosa para o cidadão. Aqui se aplica também o princípio da proporcionalidade.

Destaque-se que, em situações de crise econômica, a possibilidade de restrições a direitos sociais se mostra ainda mais defensável, sem prejuízo da necessidade de aplicação dos princípios do Estado de Direito, como o da proporcionalidade. Foi o que entendeu o Tribunal Europeu de Direitos Humanos ao negar pedido de cidadã portuguesa que teve reduzido o valor de sua aposentadoria pela aplicação, temporária, de uma "contribuição extraordinária de solidariedade", prevista por lei e aplicada por dois anos apenas, para efeito de obtenção de recursos visando a garantir o cumprimento de obrigações assumidas pelo Estado Português para obviar os efeitos da crise instalada a partir de 2008. O valor deduzido de uma aposentadoria bruta de 1.980,72 euros foi de 91,92 euros mensais. O Tribunal Europeu entendeu que a medida não violou a Convenção Europeia de Direitos do Homem e que se baseou em uma situação de interesse público comprovada, foi encaminhada por instrumento normativo adequado e se mostrou proporcional ${ }^{37}$.

\section{CONSIDERAÇÕES FINAIS}

Conforme destacado ao longo deste estudo, a implementação de um sistema de proteção social demanda racionalidade e planejamento, que se manifestam na constatação de que, como todos os direitos têm custos para a sociedade, é necessário se preocupar com o financiamento e a sustentabilidade da previdência social.

Também são necessários ajustes com o propósito de impedir a concorrência entre os subsistemas da seguridade social, o que pode conduzir à informalidade, ao esvaziamento da previdência social e à consequente redução da arrecadação tributária.

As reformas assumem papel decisivo na atualização e reconstrução das normas que ditam os comportamentos humanos desejáveis e estruturam a adequada intervenção do Estado nas relações. Nesse contexto, parece claro que a realidade social que amparou a promulgação da Constituição de 1988 é bem diferente do contexto social da atualidade.

Contrapôs-se, outrossim, o retrocesso social à ideia de sustentabilidade. Partindo-se do pressuposto de que todo direito tem custos, em um cenário de escassez de recursos e de explosão do gasto público, reformas e ajustes são as únicas alternativas capazes de reequilibrar o sistema protetor.

Evidentemente, a reorganização do modelo proposto não é definitiva, afinal, como anunciado por Heráclito de Éfeso, "tudo flui, nada persiste nem 
permanece o mesmo". Nesse sentido, se o Direito foi construído para estabilizar relações, precisa de maturidade para acompanhar a dinâmica social. Há, evidentemente, limites para a mudança, mas não se pode considerar um pretenso princípio de proibição de retrocesso como regra absoluta. Há que se respeitar os direitos adquiridos e a dignidade da pessoa, impondo verificar a presença de justificativas para as mudanças, a proporcionalidade e razoabilidade das modificações efetuadas, a existência de alternativas ou compensações para aqueles afetados pelas alterações e o estabelecimento de regras de transição, sobretudo quando se tratar de relações de longa duração como aquelas relacionadas à previdência social.

\section{REFERÊNCIAS}

BANCO NACIONAL DE DESENVOLVIMENTO ECONÔMICO E SOCIAL - BNDES. Disponível em: <http://www.bndes.gov.br/SiteBNDES/export/sites/ default/bndes_pt/Galerias/Arquivos/conhecimento/revista/rev2812.pdf.> Acessado em : 09 out. 2015.

BECK, Ulrich. Sociedade de risco. Rumo a uma outra modernidade. São Paulo: Ed. 34, 2010.

BOBBIO, Norberto. Teoria do ordenamento jurídico. Brasília: Editora Universidade de Brasília, 1999.

BOSCH, Mariano; MELGUIZO, Ángel; PAGÉS, Carmen. Melhores aposentadorias, melhores trabalhos - em direção à cobertura universal na América Latina e no Caribe. Banco Interamericano de Desenvolvimento, 2013, disponível em http://publications.iadb.org/bitstream/handle/11319/462/Melhores\%20 Aposentadorias\%20Melhores\%20Trabalhos.pdf;jsessionid=83355BD29B4DE 016B4A7CF023E2668F9? sequence=4. Acesso em: 23 dez. 2014.

BRASIL. MINISTÉRIO DA EDUCAÇÃO. Disponível em: <http://www.brasil. gov.br/educacao/2012/07/censo-2010-mostra-as-diferencas-entre-caracteristicas-gerais-da-populacao-brasileira.> Acesso em: 10 out. 2015.

BRASIL. MINISTÉRIO DA EDUCAC̣ÃO. Disponível em: <http://www.brasil. gov.br/cidadania-e-justica/2015/03/mulheres-representam-54-da-populacao-que-superou-a-extrema-pobreza.> Acesso em: 10 out. 2015.

BRASIL. MINISTÉRIO DA EDUCAÇÃO. Disponível em: <http://www.brasil. gov.br/educacao/2015/03/mulheres-sao-maioria-no-ingresso-e-na-conclusao-de-cursos-superiores. Acesso em: 10 out. 2015.

CANARIS, Claus-Wilhelm. Pensamento Sistemático e Conceito de Sistema na Ciência do Direito. Lisboa: Fundação Calouste Gulbenkian, 1989.

CANOTILHO, J.J. Gomes. Direito constitucional e teoria da constituição. 7.ed. Coimbra: Almedina, 2003. 
DEPARTAMENTO INTERSINDICAL DE ESTATÍSTICA E ESTUDOS SOCIOECONÔMICOS - DIEESE. Nota Técnica 130. Fator previdenciário: por que mudar? Disponível em: <http://www.dieese.org.br/notatecnica/2013/ notaTec130fatorPrevidenciario.pdf.> Acesso em: 09 out. 2015.

EUROPEAN UNION. Communication from the Commission to the European Parliament, the Council, the European Economic and Social Committee and the Committee of the Regions - Towards Common Principles of Flexicurity: More and better jobs through flexibility and security $\{\operatorname{SEC}(2007)$ 861\}\{SEC(2007) 862\}. Disponível em: <http://eur-lex.europa.eu/legal-content/ EN/ALL/;ELX_SESSIONID=jT1KJx5KTMKLLwnnLrnTSvn3Q0Nz16QPyyZ DYm8KCYtYxggRN7pT!-639629260?uri=CELEX:52007DC0359> Acesso em: 23 dez. 2014.

ESTADO DE SÃO PAULO. Disponível em: <http://economia.estadao.com. $\mathrm{br} /$ noticias/geral,formula-8595-e-a-melhor-para-aposentados-diz-ministro-da-previdencia,1638004>. Acesso em: 20 dez. 2015.

GALDINO, Flávio. O custo dos direitos. In TORRES, Ricardo Lobo (org.). Legitimação dos direitos humanos. Rio de Janeiro: Renovar, 2002.

GUERRA FILHO, Willis Santiago. Teoria da Ciência Jurídica. 2. ed. São Paulo: Saraiva, 2009.

HOLMES, Stephen ; SUNSTEIN, CASS. The Costs of Rights: Why Liberty Depends on Taxes. Nova Iorque-Londres: W.W. Norton \& Company, 1999.

INSTITUTO BRASILEIRO DE GEOGRAFIA E ESTATÍSTICA - IBGE. Disponível em: <http://www.ibge.gov.br/home/estatistica/populacao/projecao_da_populacao/2008/piramide/piramide.shtm. Acesso em 13/09/2015>. Acesso em: 20 Dez. 2015.

LUHMANN, Niklas. Introdução à Teoria dos Sistemas. Petrópolis: Vozes, 2009. . Sociologia do Direito I. Trad. Gustavo Bayer. Rio de Janeiro: Edições Tempo Brasileiro, 1983.

. Sociologia do Direito II. Trad. Gustavo Bayer. Rio de Janeiro: Edições Tempo Brasileiro, 1983.

MARTINS, Marcus Vinícius Silva. O pensamento de Heráclito: uma aproximação com o pensamento de Parmênides. Dissertação de Mestrado. Brasília: UnB, 2007

MATURANA, Humberto; VARELA, Francisco. A árvore da vida. As bases biológicas do entendimento humano. Campinas: Editorial Psy II, 1995.

MENDES, Gilmar Ferreira; COELHO, Inocêncio Mártires ; BRANCO, Paulo Gustavo Gonet. Hermenêutica Constitucional e Direitos Fundamentais. Brasília: Brasília Jurídica, 2000. 
MIRANDA, Jorge. Manual de Direito Constitucional. Tomo IV. Coimbra: Coimbra Editora, 2000.

NOVAIS, Jorge Reis. O Tribunal Constitucional e os direitos sociais: o direito à segurança social. In Direitos Fundamentais - Trunfos contra a maioria. Coimbra: Coimbra Editora, 2006.

NOZICK, Robert. Anarquia, Estado e Utopia. São Paulo: Martins Fontes, 2011.

PIERDONÁ, Zélia Luíza. A aposentadoria do servidor público e as normas de transição da Emenda Constitucional 20/1998, Revista de Direito Social, n. 1, p. 99-100.

SARLET, Ingo Wolfgang. A eficácia dos direitos fundamentais. 3a. ed. Porto Alegre: Livraria do Advogado, 2003.

STRECK, Lênio. Justiça lotérica - ativismo judicial não é bom para a democracia. Disponível em: <http://www.conjur.com.br/2009-mar-15/entrevista-lenio-streck-procurador-justica-rio-grande-sul>. Acesso em: 11 out. 2015.

VIEIRA DE ANDRADE, José Carlos. O "Direito ao Mínimo de Existência Condigna" como Direito Fundamental a Prestações Estaduais Positivas - Uma Decisão Singular do Tribunal Constitucional - Anotação ao Acórdão do Tribunal Constitucional n. 509/02. In Jurisprudência Constitucional, n. 1, janeiro/ março de 2004, p. 4-29.

. Os Direitos Fundamentais na Constituição Portuguesa de 1976. 3a. ed. Coimbra: Almedina, 2004.

1 MARTINS, Marcus Vinícius Silva. O pensamento de Heráclito: uma aproximação com o pensamento de Parmênides. Dissertação de Mestrado. Brasília: UnB, 2007, p. 48.

2 MATURANA, Humberto, VARELA, Francisco. A árvore da vida. As bases biológicas do entendimento humano. Campinas: Editorial Psy II, 1995, p. 112.

3 HOLMES, Stephen; SUNSTEIN, Cass. The Costs of Rights: Why Liberty Depends on Taxes. Nova Iorque-Londres: W.W. Norton \& Company, 1999, p. 18 seg. e 220 seg..

4 BOBBIO, Norberto. Teoria do ordenamento jurídico. Brasília: Editora Universidade de Brasília, 1999, p. 71.

5 Plausível é a cita de Willis Santiago Guerra Filho: Sistema autopoiético é aquele dotado de organização autopoiética, em que há a (re)produção dos elementos de que se compõe o sistema e que geram sua organização pela relação reiterativa ("recursiva") entre eles. Esse sistema é autônomo porque o que nele se passa não é determinado por nenhum componente do ambiente mas sim por sua própria organização, isto é, pelo relacionamento entre seus elementos. Essa autonomia do sistema tem por condição sua clausura, quer dizer, a circunstância de o sistema ser 'fechado', do ponto de vista de sua organização, não havendo 'entradas' (inputs) e 'saídas' (outputs) para o ambiente, pois os elementos interagem no e através dele, que é 'como o agente que conecta as extremidades do sistema (como se fosse uma gigantesca sinapse) e o mantém fechado, autopoiético'. (GUERRA FILHO, Willis Santiago. Teoria da Ciência Jurídica. 2a ed. São Paulo: Saraiva, 2009, p. 209.).

6 Desconsiderando-se os regimes próprios de previdência.

7 Disponível em: <http://g1.globo.com/jornal-da-globo/noticia/2015/01/brasil-encerra-2014-com-menor-taxa-de-desemprego-ja-registrada.html>. Acesso em: 06 Dez. 2015.

8 In: 〈http://exame.abril.com.br/economia/noticias/taxa-de-desemprego-no-brasil-deve-atingir-10-em-2016〉. Acesso em: 06 Dez. 2015. 
9 Disponivel em: http://www.istoe.com.br/colunas-e-blogs/coluna/367223 DESEMPREGO+E+MANIPULACOES. Acesso em:06 Dez. 2015.

10 Para o BPC os dados são de 2012 e foram obtidos no sítio do Ministério do Desenvolvimento Social e Combate à Fome. Disponivelem: <http://www.mds.gov.br/assistenciasocial/beneficiosassistenciais/bpc. > Acesso em: 09 Jan. 2015.

11 BOSCH, Mariano; MELGUIZO, Ángel; PAGÉS, Carmen. Melhores aposentadorias, melhores trabalhos - em direção à cobertura universal na América Latina e no Caribe. Banco Interamericano de Desenvolvimento, 2013, p. 66. Disponível em: <http://publications.iadb.org/bitstream/handle/11319/462/ Melhores\%20Aposentadorias\%20Melhores\%20Trabalhos.pdf;jsessionid=83355BD29B4DE016B4A7CF 023E2668F9? sequence=4.> Acesso em: 23 Dez. 2014.

12 Inclusive, essa compreensão foi firmada nos autos do REsp 1112557/MG, julgado sob o rito de recurso representativo de controvérsia. Vejamos:

RECURSO ESPECIAL REPETITIVO. ART. 105, III, ALÍNEA C DA CF. DIREITO PREVIDENCIÁRIO. BENEFÍCIO ASSISTENCIAL. POSSIBILIDADE DE DEMONSTRAÇÃO DA CONDIÇÃO DE MISERABILIDADE DO BENEFICIÁRIO POR OUTROS MEIOS DE PROVA, QUANDO A RENDA PER CAPITA DO NÚCLEO FAMILIAR FOR SUPERIOR A 1/4 DO SALÁRIO MÍNIMO. RECURSO ESPECIAL PROVIDO. 1. A CF/88 prevê em seu art. 203, caput e inciso V a garantia de um salário mínimo de benefício mensal, independente de contribuição à Seguridade Social, à pessoa portadora de deficiência e ao idoso que comprovem não possuir meios de prover à própria manutenção ou de tê-la provida por sua família, conforme dispuser a lei. 2. Regulamentando o comando constitucional, a Lei no 8.742/93, alterada pela Lei 9.720/98, dispõe que será devida a concessão de benefício assistencial aos idosos e às pessoas portadoras de deficiência que não possuam meios de prover à própria manutenção, ou cuja família possua renda mensal per capita inferior a 1/4 (um quarto) do salário mínimo. 3. O egrégio Supremo Tribunal Federal, já declarou, por maioria de votos, a constitucionalidade dessa limitação legal relativa ao requisito econômico, no julgamento da ADI 1.232/DF (Rel. para o acórdão Min. NELSON JOBIM, DJU 1.6.2001). 4. Entretanto, diante do compromisso constitucional com a dignidade da pessoa humana, especialmente no que se refere à garantia das condições básicas de subsistência física, esse dispositivo deve ser interpretado de modo a amparar irrestritamente a o cidadão social e economicamente vulnerável. 5. A limitação do valor da renda per capita familiar não deve ser considerada a única forma de se comprovar que a pessoa não possui outros meios para prover a própria manutenção ou de tê-la provida por sua família, pois é apenas um elemento objetivo para se aferir a necessidade, ou seja, presume-se absolutamente a miserabilidade quando comprovada a renda per capita inferior a $1 / 4$ do salário mínimo. 6. Além disso, em âmbito judicial vige o princípio do livre convencimento motivado do Juiz (art. 131 do CPC) e não o sistema de tarifação legal de provas, motivo pelo qual essa delimitação do valor da renda familiar per capita não deve ser tida como único meio de prova da condição de miserabilidade do beneficiado. De fato, não se pode admitir a vinculação do Magistrado a determinado elemento probatório, sob pena de cercear o seu direito de julgar. 7. Recurso Especial provido. (REsp 1112557/MG, Rel. Ministro NAPOLEÃO NUNES MAIA FILHO, TERCEIRA SEÇÃO, julgado em 28/10/2009, DJe 20/11/2009)

13 Sobre a Justiça Lotérica, vale a pena conferir a entrevista de Lênio Streck para o CONJUR. Disponível em: <http://www.conjur.com.br/2009-mar-15/entrevista-lenio-streck-procurador-justica-rio-grande-sul.> Acesso em 11 Out. 2015.

14 Referida medida provisória foi convertida na Lei 13.135/15, porém a redução do valor da pensão não foi aprovada no Congresso Nacional.

15 BRASIL. Presidencia da Republica. Disponível em: <http://www.planalto.gov.br/ccivil_03/_Ato20112014/2014/Mpv/mpv664.htm.> Acesso em 22 Mar. 2015.

16 Disponível em: http://dinheiropublico.blogfolha.uol.com.br/2013/10/20/em-dez-anos-de-bolsa-familia-gastos-em-assistencia-sao-os-que-mais-crescem/ >. Acesso em 23 Dez. 2015.

17 Disponível em: <http://www.brasil.gov.br/cidadania-e-justica/2015/06/orcamento-garante-aumento-de-recursos-para-bolsa-familia>. Acesso em 23 Dez. 2015.

18 NOZICK, Robert. Anarquia, Estado e Utopia. São Paulo: Martins Fontes, 2011, Prefácio, p. X.

19 GALDINO, Flávio. O custo dos direitos. In: TORRES, Ricardo Lobo (org.). Legitimação dos direitos humanos. Rio de Janeiro: Renovar, 2002, p. 215

20 Nesse sentido, SARLET, Ingo Wolfgang, A eficácia dos direitos fundamentais. 3. ed. Porto Alegre: Livraria do Advogado, 2003.p. 166-167 e 190 e ss.

21 Ibidem, p. 257. 
22 CANOTILHO, J. J. Gomes, Direito constitucional e teoria da constituição. 7.ed. Coimbra: Almedina, 2003, p. 476-478.

23 Relator Ministro Celso de Mello. Julgamento proferido em 29.04.2004 e noticiado no Informativo 345 do Supremo Tribunal Federal. Impugnou-se, na espécie, veto presidencial aposto a dispositivo de projeto de lei de diretrizes orçamentárias que disciplinava a aplicação de recursos públicos em despesas com saúde. A ADPF foi julgada prejudicada em virtude da edição de outra lei que restaurou o conteúdo do dispositivo vetado, suprindo a lacuna decorrente.

24 CANOTILHO, J. J. Gomes, Direito constitucional e teoria da constituição. 7.ed. Coimbra: Almedina, 2003, p. 336-338.

25 MIRANDA, Jorge. Manual de Direito Constitucional. Tomo IV. Coimbra: Coimbra Editora, 2000., p. 397.

26 CANOTILHO, J. J. Gomes, Direito constitucional e teoria da constituição. 7.ed. Coimbra: Almedina, 2003 , p. 337.

27 São exemplos apresentados por J. J. Gomes Canotilho, Ibidem. p. 337.

28 Adota-se, aqui, o entendimento de José Carlos Vieira de Andrade (Os direitos fundamentais na Constituição portuguesa de 1976, 3.ed. Coimbra: Almedina, 2004). p. 406 e ss., e também "O "Direito ao Mínimo de Existência Condigna" como Direito Fundamental a Prestações Estaduais Positivas - Uma Decisão Singular do Tribunal Constitucional - Anotação ao Acórdão do Tribunal Constitucional n. 509/02. In Jurisprudência Constitucional, n. 1, janeiro/março de 2004, p. 4-29.

29 Conferir o voto. Disponivel em: < http://www.stf.jus.br/arquivo/cms/noticiaNoticiaStf/anexo/Voto ADI1923LF.pdf> Acesso em: 20 Dez. 2015. p. 18.

30 VIEIRA DE ANDRADE, José Carlos. Os Direitos Fundamentais na Constituição Portuguesa de 1976. 3.ed. Coimbra: Almedina, 2004, p. 409.

31 Nesse sentido, examine-se CANOTILHO, J.J. Gomes. Direito constitucional e teoria da constituição. 7.ed. Coimbra: Almedina, 2003, p. 339-340), que, não obstante, adota posição um tanto quanto diversa da de Vieira de Andrade, admitindo o princípio do não retrocesso social como cláusula garantidora da irreversibilidade dos direitos adquiridos, em violação flagrante ao princípio da proteção da confiança e da segurança dos cidadãos no âmbito econômico, social e cultural, bem como ao núcleo essencial já efetivado da existência mínima inerente à dignidade da pessoa. Seriam inconstitucionais, portanto, as medidas estatais que, sem a criação de outros esquemas alternativos ou compensatórios, materializem uma pura e simples anulação, revogação ou aniquilação do referido núcleo essencial.

32 VIEIRA DE ANDRADE, José Carlos. Os Direitos Fundamentais na Constituição Portuguesa de 1976. 3.ed. Coimbra: Almedina, 2004, p. 411.

33 O Tribunal Constitucional e os Direitos Sociais $\square$ O Direito à Segurança Social, Direitos Fundamentais - Trunfos contra a Maioria. Coimbra: Coimbra Editora, 2006, p. 197-198.

34 Nesse sentido, examinar a obra MENDES, Gilmar Ferreira; COELHO, Inocêncio Mártires; BRANCO, Paulo Gustavo Gonet. Hermenêutica Constitucional e Direitos Fundamentais. Brasília: Brasília Jurídica, 2000, p. 251 e ss., bem como as decisões proferidas pela Corte Maior na Representação 1.077, na ADIn 855 e na Suspensão de Segurança 1.320, dentre outras.

35 CANARIS, Claus-Wilhelm. Pensamento Sistemático e Conceito de Sistema na Ciência do Direito. Lisboa: Fundação Calouste Gulbenkian, 1989, p. 18 e ss.

36 Examinar, a propósito, PIERDONÁ, Zélia Luíza. A aposentadoria do servidor público e as normas de transição da Emenda Constitucional 20/1998, Revista de Direito Social, n. 1, p. 99-100.

37 O inteiro teor da decisão, em inglês, Disponivel em: http://s.conjur.com.br/dl/corte-europeia-aposentadoria-portugal.pdf $>$. Acesso em 16 Dez. 2015. 


\title{
DOWNTURN, PROGRESSION, EXPANSION AND RETROGRESSION: A HEALTHY PATH TO BALANCED SOCIAL PROTECTION
}

\begin{abstract}
Changes arise at every moment, imposing adjustments and calibrations on the rules that regulate human relations. In the field of social rights, the reality is not different. External factors, such as wars, as well as socio-economic evolution and technological advances, began to claim a more energetic posture from the State, which has ceased to be an absentee entity to become a normalizer agent of the legal relations, with strong protective intervention. Nevertheless, the State's magnitude, the disorganized growth of the protective system and the chronic disequilibrium in the public accounts, combined with demographic changes, started to show signs of retraction in the model of hypertrophic protection. Brazilian reality also has experimented the discomfortable transition between the models of expansion and regression of rights, with two circumstances: in Brazil, protection arrangements were not properly built, but imported from other countries and delivered to the people as donations and political offers, established without suitable planning. The result of legislative disregard was the comprehension that a vulnerable protective system has ephemeral lastingness, which leads to the necessity of reforms directed through containment and austerity measures. The work seeks to highlight notably three aspects: 1 st) the importance of a careful planning in establishing a safe and sustainable model of social protection; 2 nd) the absolute need of improvements and regulatory adjustments to accommodate generous selectivity criteria; and 3rd) the implementation of containment measures, although it involves the reduction of the standard protective quality, does not characterize social retrogression, but the resumption of the path towards balance, and coherence.

KEYWORDS: Social Benefits. Social Retrogression. Welfare Reforms.
\end{abstract}

Submetido: 28 dez. 2015

Artigo convidado 